\title{
Ultrasound Diameter of the Portal Vein to Healthy Adult in Parakou (Benin)
}

\author{
Djivèdé Akanni1 ${ }^{*}$, Khadidjatou Sake Alassan², Miralda Kiki'1, Babylas Djohoun1, \\ Kofi-Mensa Savi de Tove ${ }^{1}$, Jean Sehonou ${ }^{3}$ \\ ${ }^{1}$ Medical Imaging Department, Faculty of Medicine, University of Parakou, Parakou, Benin \\ ${ }^{2}$ Hepato Gastro Enterology Department, Faculty of Medicine, University of Parakou, Parakou, Benin \\ ${ }^{3}$ Hepato Gastro Enterology Department, Faculty of Health Sciences, University of Abomey Calavi, Cotonou, Benin \\ Email: *djivakanni@yahoo.fr
}

How to cite this paper: Akanni, D., Sake Alassan, K., Kiki, M., Djohoun, B., Savi de Tové, K.-M. and Sehonou, J. (2021) Ultrasound Diameter of the Portal Vein to Healthy Adult in Parakou (Benin). Open Journal of Medical Imaging, 11, 145-152. https://doi.org/10.4236/ojmi.2021.114013

Received: November 5, 2021

Accepted: December 24, 2021

Published: December 27, 2021

Copyright (c) 2021 by author(s) and Scientific Research Publishing Inc. This work is licensed under the Creative Commons Attribution-NonCommercial International License (CC BY-NC 4.0). http://creativecommons.org/licenses/by-nc/4.0/

\section{Open Access}

\begin{abstract}
Introduction: The portal vein (PVD) diameter is one of the predictive variables of portal hypertension. This diameter can differ according to the population. The objective of this study was to determine the PVD in a healthy adult population in Parakou using ultrasonography. Methods: A cross-sectional descriptive study was conducted in the medical imaging department of the Borgou and Alibori University-affiliated Hospitals in Parakou from July 1 st to October 1st, 2019. The study population consisted of 201 healthy adults. The ultrasound diameter of the portal vein was measured at the level of the hepatic hilum on a cross-sectional epigastric view and on an oblique intercostal view. An association was sought between the PVD and sociodemographic and anthropometric factors. Results: The mean age was $28.97 \pm 10.56$ years and the sex ratio $(\mathrm{M} / \mathrm{F})$ was 0.79 . The mean PVD in regular breathing (FB) was $9.83 \pm 0.95 \mathrm{~mm}$ with a $95 \%$ confidence interval of [9.70; 9.97], a 95th percentile of $11.49 \mathrm{~mm}$ with extremes of $7.50 \mathrm{~mm}$ and $12.23 \mathrm{~mm}$. PVD was correlated with age, sex, weight, height and abdominal girth. After multiple linear regressions $(r=0.19)$, there was correlation between the PVD in normal breathing with age $(\mathrm{p}=0.0090)$, weight $(\mathrm{p}=0.0026)$, body mass index $(\mathrm{p}=$ $0.0171)$ and body surface $(\mathrm{p}=0.004)$. Conclusion: A PVD greater in normal adults is less than $12 \mathrm{~mm}$ and seems to be correlated to the subject age, weight, body mass index and body surface. A more than $13 \mathrm{~mm}$ PVD should lead to the suspicion of portal vein hypertension in adults in our populations.
\end{abstract}

\section{Keywords}

Portal Vein, Ultrasound, Portal Vein Hypertension, Parakou 


\section{Introduction}

The portal vein (PVD) diameter and the portal vein flow are part of the monitoring parameters in patient with cirrhosis to depict portal vein hypertension (PVH). PVH is defined as an increase in pressure of the portal venous system with a systemic to portal pressure gradient greater than $5 \mathrm{mmHg}$ [1] [2]. It is the most frequent complication in patients with cirrhosis [2] [3].

The reference method for the diagnosis of $\mathrm{PVH}$ is catheterization of the perihepatic veins [4], which is an invasive technique not available in our context. The clinical manifestations of PVH are late-onset. Splenomegaly is the first sign to appear but already indicates advanced PVH [2].

Imaging with Doppler ultrasound allows diagnosis based on the study of the blood flow in the portal vein before the occurrence of changes in diameter. In our context, Doppler-equipped ultrasound devices are not widely available. Thus, B-mode ultrasonography, which measures the diameter of the portal vein as an indirect reflection of the portal pressure, is the most accessible and widely used technique [5] [6].

In the various studies and depending on the country, the normal diameter of the vein and the threshold value for the diagnosis of PVH varied [7] [8].

The upper limit of normality of portal vein diameter was found to be $14.5 \mathrm{~mm}$ [7].

It is with a view to determining the normal diameter of the portal vein in our population that this work was initiated.

\section{Methods}

This was a cross-sectional, descriptive study with prospective data collection. It was conducted from July 1st to October 1st, 2019 in the Medical Imaging Department of the National University Hospital Center of Borgou and Alibori Department (DNUHC-B/A) of Parakou in Benin.

Participants of 18-year-old and more, residing in Parakou and who had given informed consent were included in the study. Subjects with diabetes mellitus, amenorrhea (pregnant or not), a history of hepatobiliary disease, clinical signs of hepatopathy (hepatomegaly, signs of portal hypertension, etc.) or cardiovascular disease (hypertension, cardiac failure, etc.) were not included. We excluded subjects who could not perform deep breathing, those in whom ultrasound revealed hepatobiliary or splenic abnormalities, those with a pregnant uterus on ultrasound and subjects in whom the portal vein could not be measured satisfactorily (obese subjects, subjects with excess gas).

An abdominopelvic ultrasound was performed by the radiologist after fasting period of at least 06 hours. The examination was performed in B mode using a Mindray ultrasound machine, model Digi Prince 8800 plus ${ }^{\circledR}$ equipped with two multi-frequency probes, one low-frequency convex $(2.5-5 \mathrm{MHz})$ and the other high-frequency linear $(5-10 \mathrm{MHz})$. The diameter of the portal vein was measured in its extrahepatic portion at the hepatic hilum where its visualization was 
optimal. This measurement was performed in normal breathing (NB), in deep exhalation (DE), and in deep inspiration (DI). All measurements were taken three times by the same radiologist and averaged to improve the accuracy of the results and reduce the influence of intra-observer variability.

Other variables were weight, height, BMI, body surface and abdominal circumference. Patients' heights were measured in standing position using a height gauge with the head in Frankfurts' position after removing their shoes. Weight was measured using a weighing scale to the nearest $0.1 \mathrm{~kg}$. Both measurements were used to calculate the BMI and body surface area. Abdominal circumference was measured at the level of the umbilicus using a measuring tape.

The data collected was recorded in the Epi data manager software and the analysis of these data was carried out using EPI INFO v7.2, EpiData analysis v2.2.3.187 and SPSS 22. The averages were compared by using either the Student test (Anova) or Wilcoxon test as appropriate. An association was sought between the PVD and sociodemographic factors (age, gender, ethnicity) and between the PVD and anthropometric factors (weight, height, BMI, body surface, abdominal circumference). A two-by-two bi-variate analysis followed by multiple linear regression was used. A p-value of less than 0.05 was considered significant.

This study is performed in accordance with the study protocol, the Declaration of Helsinki (October 2013) and the WHO Handbook for Good Clinical Research Practice (July 2002) as well as any other applicable national and other regulatory guidelines in Benin. The free and informed consent of all the subjects surveyed was obtained. All data collected during our survey were used only for the purposes of this study and remained confidential. We received authorisation from the CLERB-UP (Local Ethics Committee for Biomedical Research of the University of Parakou) for our study.

\section{Results}

\subsection{Description of the Study Population}

A total of 201 subjects were included. The mean age was $28.97 \pm 10.56$ years with a median of 25 years and extremes of 18 and 75 years. Females were the most represented $(55.72 \%)$ with a sex ratio $(\mathrm{M} / \mathrm{F})$ of 0.79 . The study population generally had a normal BMI (64.68\%) according to the WHO IMC classification. Table 1 shows the distribution of the study population according to anthropometric data.

\subsection{Ultrasound Diameter of the Portal Vein}

The mean ultrasound diameter in normal breathing of the portal vein was $9.83 \pm$ $0.95 \mathrm{~mm}$ with extremes of $7.50 \mathrm{~mm}$ and $12.23 \mathrm{~mm}$. The 95th percentile of DPV in FB was $11.49 \mathrm{~mm}$. Table 2 shows the distribution of the mean DPV as a function of respiratory maneuvers. Figure 1 illustrates the variations in portal vein diameter as a function of respiratory maneuvers. 
Table 1. Anthropometric parameters of the study population.

\begin{tabular}{ccccccccc}
\hline & Min & 1st Q & Mean & Gap-T & Med & 3rd Q & Max & IC 95\% \\
\hline Weight & 39.00 & 57.00 & $\mathbf{6 5 . 1 8}$ & $\mathbf{1 1 . 7 2}$ & 64.00 & 71.00 & 109.00 & $63.55-66.81$ \\
Height & 1.50 & 1.62 & 167 & $\mathbf{0 . 0 7}$ & 1.68 & 1.73 & 1.94 & $1.66-1.68$ \\
BMI & 15.62 & 20.04 & 23.35 & $\mathbf{4 . 3 9}$ & 22.58 & 25.96 & 43.66 & $22.74-23.96$ \\
Abdo circumf & 60.00 & 72.00 & $\mathbf{8 0 . 3 7}$ & $\mathbf{1 1 . 5 8}$ & 78.00 & 87.00 & 120.00 & $78.77-81.99$ \\
Body surface & 1.30 & 1.62 & $\mathbf{1 . 7 3}$ & $\mathbf{0 . 1 6}$ & 1.72 & 1.82 & 2.18 & $1.71-1.76$ \\
\hline
\end{tabular}

Mean \pm Gap-T $=$ Mean \pm standard deviation, 1st - 3rd Quartile, Med = Median, Min = Minimum, Max $=$ Maximum, 95\% CI: 95\% Confidence Interval.

Table 2. PVD in normal breathing, DI, and DE.

\begin{tabular}{ccccccccc}
\hline & Min & 1st Q & Mean & Gap-T & Med & 3rd Q & Max & IC 95\% \\
\hline NB & 7.50 & 9.20 & 9.83 & 0.95 & 9.90 & 10.40 & 12.23 & $9.70-9.97$ \\
DI & 8.00 & 10.00 & 10.87 & 1.12 & 10.90 & 11.65 & 13.90 & $10.71-11.03$ \\
DE & 6.30 & 8.10 & 8.72 & 0.93 & 8.70 & 9.40 & 11.00 & $8.59-8.85$ \\
\hline
\end{tabular}

Mean \pm Gap- $\mathrm{t}=$ Means \pm standard deviations, Medians, 1 st -3 rd Quartile, Min $=$ Minimum, Max = Maximum.

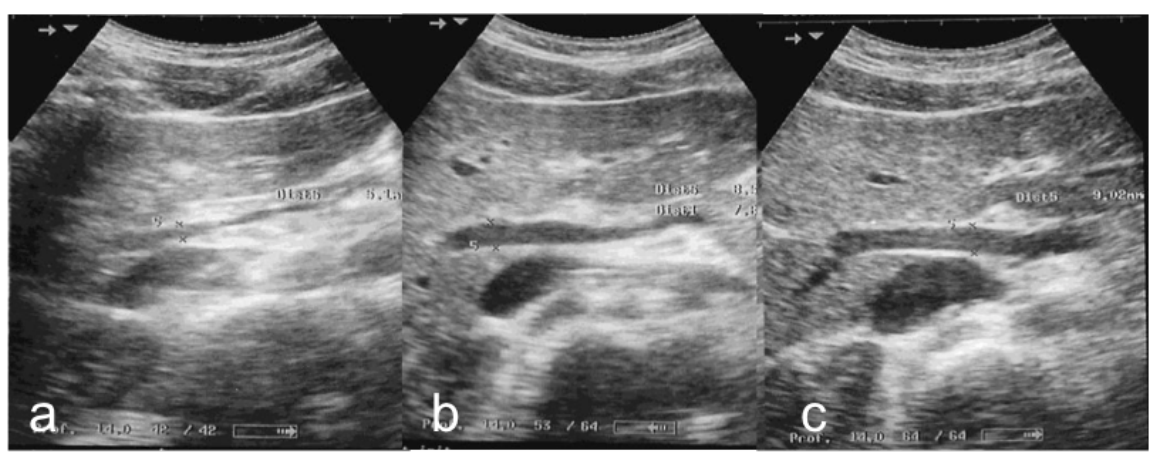

Figure 1. Diameter of the portal vein at different stages of respiration (a) In deep exhalation, (b) In free/normal breathing, (c) In deep inspiration.

\subsection{Factors Influencing the Diameter of the Portal Vein}

After simple linear regression (Table 3), there was no correlation between the PVD in normal breathing with body mass index. On the other hand, the PVD in normal breathing was correlated with age, gender, weight, height, abdominal girth and body surface.

After multiple linear regressions (Table 4), there was correlation between the PVD in normal breathing with age, weight, body mass index and body surface.

\section{Discussion}

The free-breathing DPV in our study ranged from 7.5 to $12.33 \mathrm{~mm}$ with an average of $9.83 \pm 0.95 \mathrm{~mm}$. These results are within the range of what is conventionally reported. Table 5 reports the different DPV values found in other 
Table 3. Factors influencing the PVD in simple linear regression.

\begin{tabular}{ccccc}
\hline & Beta Coefficient & Es & r & p-value \\
\hline Age & 0.02 & 0.01 & 0.05 & 0.0019 \\
Gender & -0.46 & 0.13 & 0.06 & 0.0005 \\
Abdominal girth & 0.02 & 0.01 & 0.05 & 0.0024 \\
Weight & 0.02 & 0.01 & 0.06 & 0.0005 \\
Height & 0.03 & 0.01 & 0.07 & 0.0002 \\
BMI & 0.03 & 0.01 & 0.01 & 0.0838 \\
Body surface & 0.00 & 0.00 & 0.10 & $<0.0000$ \\
\hline
\end{tabular}

Table 4. Factors influencing the PVD in multiple linear regression.

\begin{tabular}{cccc}
\hline & Beta Coefficient & Es & p-value \\
\hline Age & 0.02 & 0.01 & 0.0090 \\
Weight & -0.31 & 0.10 & 0.0026 \\
BMI & 0.24 & 0.01 & 0.0171 \\
Body Surface & 0.02 & 0.00 & 0.0004 \\
\hline
\end{tabular}

Coefficient of correlation $r=0.19$.

Table 5. DPV value according to other authors.

\begin{tabular}{cccc}
\hline & Year & Country & PVD $^{*}(\mathrm{~mm})$ \\
\hline Bellamy et al. [17] & 1984 & England & $7.2 \pm 2.3$ \\
Hawaz et al. [19] & 2012 & Ethiopia & $7.9 \pm 2$ \\
Saha et al. [23] & 2015 & India & $8.83 \pm 2.12$ \\
Rahim et al. [11] & 1985 & England & $8.76 \pm 1.5$ \\
Rokni et al. [13] & 2005 & Iran & $8.9 \pm 1.08$ \\
Rokni et al. [14] & 2006 & Iran & $9.36 \pm 1.65$ \\
Luntsi et al. [18] & 2016 & Nigeria & $9.60 \pm 1.41$ \\
Mildenberger et al. [12] & 1987 & Germany & $9.7 \pm 1.7$ \\
Our study & 2019 & Benin & $9.83 \pm 0.95$ \\
Lal et al. [7] & 2018 & India & $10.2 \pm 1.47$ \\
Adeyekun et al. [20] & 2014 & Nigeria & $10.3 \pm 1.5$ \\
Geleto et al. [8] & 2016 & Ethiopia & $10.6 \pm 1.8$ \\
Wiersema et al. [16] & 1995 & United States & $10.7 \pm 1.7$ \\
Gareeballah et al. [22] & 2017 & Sudan & $10.73 \pm 1.47$ \\
Usman et al. [9] & 2015 & Nigeria & $10.87 \pm 0.81$ \\
Weinreb et al. [10] & 1982 & United States & $11.00 \pm 2$ \\
Anakwue et al. [21] & 2009 & Nigeria & $11.45 \pm 1.49$ \\
Cosar et al. [15] & 2004 & Turkey & $11.68 \pm 0.26$ \\
\hline
\end{tabular}

${ }^{*}$ mean \pm Gap-T. 
studies. The variations between the different studies could be explained not only by racial variations but also by the measurement technique used, different maneuvers performed to better visualize the portal vein and the cooperation of the subject who performs them [7] [9]-[23].

Socio-demographic and anthropometric characteristics are variably correlated with PVD in the different studies. In our study, the factors associated with PVD after simple linear regression were: age, gender, weight, height, abdominal girth and body surface.

Adeyekun et al. [20] in Nigeria in 2014, Weinreb et al. [10] in the United States in 1982, Cosar et al. [15] in Turkey in 2004 found no factors associated with PVD. Usman et al. [9] and Geleto et al. [8] found only age and sex as associated factors in their studies in Nigeria in 2015 and Ethiopia in 2016 respectively. Weight and height were associated factors in Gareeballah et al. [22] in Sudan in 2017, Saha et al. [23] in India in 2015.

As in our study, Lal et al. [7] in India in 2018, after a bivariate analysis found sex, weight, height and abdominal girth as associated factors. After multiple linear regression, they found height as the only factor weakly associated with PVD.

The interest of measuring the average DPV is to be able to determine the threshold at which portal hypertension can be suspected. This threshold in case of chronic hepatopathy varies between 12 and $15 \mathrm{~mm}$ according to different recommendations [8] [24]. Among the various recommendations concerning the PVD threshold value for the diagnosis of PVH, the one that comes closest to our results comes from SIAD (abdominal and digestive imaging society). According to its recommendations, PVH should be suspected in a patient with chronic liver disease when the PVD measured outside the hepatic parenchyma is greater than $12 \mathrm{~mm}[1]$.

In the present study, 95\% of the population (95th percentile) had a PVD less than or equal to $11.49 \mathrm{~mm}$ and the maximum value found was $12.33 \mathrm{~mm}$. Pending further studies necessary to determine the precise threshold value for the diagnosis of PVH, Parakou should suspect PVH when the PVD is greater than 13 $\mathrm{mm}$ in cases of chronic liver disease.

The main limitation of this study is the lack of biological assessments. This did not allow us to verify the normality of the liver tests in the participants and thus formally rule out a hepatopathy.

\section{Conclusion}

The adult PVD diameter in Parakou is on average $9.83 \pm 0.95 \mathrm{~mm}$ with a 95th percentile of $11.49 \mathrm{~mm}$. Pending further studies, a PVD greater than $13 \mathrm{~mm}$ should lead to the suspicion of PVH in adults in our populations. It has shown an association between age, weight, BMI and body surface with PVD.

\section{Conflicts of Interest}

The authors declare no conflicts of interest regarding the publication of this paper. 


\section{References}

[1] Godat, S., Antonino, A.T., Dehlavi, M.A., Moradpour, D. and Doerig, C. (2012) Portal Hypertension and Management of Ascites. Revue Médicale Suisse, 352, 1665-1668.

[2] Guillaume, M., Cervoni, J.P., Chagneau-Derrode, C., Plessier, A. and Carbonell, N. (2015) Portal Hypertension: Pathophysiology, Causes, Diagnosis and Treatment. Hepato-Gastro and Digestive Oncology, 22, 40-56.

[3] Sehonou, J., Kodjoh, N., Sake, K. and Mouala, C. (2010) Hepatic Cirrhosis in Cotonou (Republic of Benin): Clinical Aspects and Factors Related to Death, Medecine tropicale, 40, 11-14.

[4] Vanbiervliet, G., Pomier-Layrargues, G. and Huet, P.-M. (2005) Invasive Diagnosis of Portal Hypertension in Cirrhosis: A Critical Evaluation of the Hepatic venous Pressure Gradient Measurement. Gastroentérologie Clinique et Biologique, 10, 988-996. https://doi.org/10.1016/S0399-8320(05)88171-0

[5] Sonhaye, L., Amadou, A., Tchaou, M., Gbande, P., Kolou, B., Assih, K., et al. (2015) Abdominal Ultrasound in the Follow-Up of the Liver Cirrhosis in Developing Country. Journal Africain d' Imagerie Médicale, 7, 253-258.

[6] Dovonou, C.A., Alassani, C.A., Sake, K., Attinsounon, C.A., Azon-Kouanou, A., Tandjiekpon, A.R., et al. (2018) Epidemiological, Clinical and Paraclinical Aspects of Cirrhosis at Borgou Departmental University Hospital Center (Benin). Open Journal of Internal Medicine, 8, 113-122. https://doi.org/10.4236/ojim.2018.82012

[7] Lal, N., Lal, V., Majumdar, S. and Moitra, S. (2018) Anthropometric Correlates of Sonographically Determined Normal Portal Vein Diameter: Results from a Study Conducted in Rajasthan, India. International Journal of Anatatomy and Research, 6, 5588-5592. https://doi.org/10.16965/ijar.2018.208

[8] Geleto, G., Getnet, W. and Tewelde, T. (2016) Mean Normal Portal Vein Diameter Using Sonography among Clients Coming to Radiology Department of Jimma University Hospital, Southwest Ethiopia. Ethiopian Journal of Health Sciences, 26, 237-242. https://doi.org/10.4314/ejhs.v26i3.6

[9] Usman, A.U., Ibinaiye, P., Ahidjo, A., Tahir, A., Sa'ad, S., Mustapha, Z., et al. (2015) Determinations of Normal Portal Vein Diameter on Ultrasound Scan among Adults in Northeastern Nigeria. Archives of International Surgery, 5, 143-148. https://doi.org/10.4103/2278-9596.167507

[10] Weinreb, J., Kumari, S., Phillips, G. and Pochaczevsky, R. (1982) Portal Vein by Real-Time Measurements Sonography. American Journal of Roentgenology, 139, 497-479. https://doi.org/10.2214/ajr.139.3.497

[11] Rahim, N. and Adam, E.J. (1985) Ultrasound Demonstration of Variations in Normal Portal Vein Diameter with Posture. British Journal of Radiology, 58, 313-314. https://doi.org/10.1259/0007-1285-58-688-313

[12] Mildenberger, P., Lotz, R. and Kreitner, K.F. (1987) Duplex Sonography of the Normal Portal Vein. Deutsche Medizinische Wochenschrift, 112, 1936-1939. https://doi.org/10.1055/s-2008-1068357

[13] Rokni Yazdi, H. and Khalilian, M.R. (2005) Sonographic Assessment of Respiratory Variations in Diameter of Portal and Splenic Veins in Cirrhotic Patients and Healthy Controls. Iranian Journal of Radiology, 2, 95-98.

[14] Rokni Yazdi, H. and Sotoudeh, H. (2006) Assessment of Normal Doppler Parameters of Portal Vein and Hepatic Artery in 37 Healthy Iranian Volunteers. Iranian Journal of Radiology, 3, 213-216.

[15] Cosar, S., Oktar, S.O., Cosar, B., Yücel, C. and Özdemir, H. (2005) Doppler and 
Gray-Scale Ultrasound Evaluation of Morphological and Hemodynamic Changes in Liver Vascualture in Alcoholic Patients. European Journal of Radiology, 54, 393-399. https://doi.org/10.1016/j.ejrad.2004.07.015

[16] Wiersema, M.J., Chak, A., Kopecky, K.K. and Wiersema, L.M. (1995) Duplex Doppler Endosonography in the Diagnosis of Splenic Vein, Portal Vein, and Portosystemic Shunt Thrombosis. Gastrointestinal Endoscopy, 42, 19-26. https://doi.org/10.1016/S0016-5107(95)70237-7

[17] Bellamy, E.A., Bossi, M.C. and Cosgrove, D.O. (1984) Ultrasound Demonstration of Changes in the Normal Portal Venous System Following a Meal. British Journal of Radiology, 57, 147-149. https://doi.org/10.1259/0007-1285-57-674-147

[18] Luntsi, G., Sani, M., Zira, J.D., Ivor, N.C. and Garba, S.H. (2016) Sonographic Assessment of the Portal Vein Diameter in Apparently Healthy Adults in a Northern Nigerian Population. African Health Sciences, 16, 1163-1168. https://doi.org/10.4314/ahs.v16i4.35

[19] Hawaz, Y., Admassie, D. and Kebede, T. (2012) Ultrasound Assessment of Normal Portal Vein Diameter in Ethiopians Done at Tikur Anbessa Specialized Hospital. East and Central African Journal of Surgery, 17, 90-93.

[20] Adeyekun, A.A. and Tsebi, H.B. (2014) Grey-Scale Sonographic Evaluation of Portal Vein Diameter in Healthy Nigerian Adults. Journal of Medicine and Biomedical Research, 13, 17-24.

[21] Anakwue, A.-M., Anakwue, R., Agwu, K.K., Idigo, F., Ugwu, A. and Nwogu, U. (2009) Sonographic Evaluation of Normal Portal Vein Diameter in Nigerians. European Journal of Scientific Research, 36, 114-117.

[22] Gareeballah, A., Hassan, I.A., Elzaki, M., Ibraheem, S.S., Abelwahab, B., Siddig, A., et al. (2017) Measurement of Normal Portal Vein Diameter in Sudanese Using Ultrasonography. Global Advanced Research Journal of Medicine and Medical sciences, 6, 336-340.

[23] Saha, N., Sarkar, R. and Singh, M.M. (2015) Portal Vein Diameter in a Tertiary Care Centre in North-East India. IOSR Journal of Dental and Medical Sciences, 14, 114-117.

[24] Dib, N., Sawadogo, A., Oberti, F. and Calès, P. (2012) Hypertension portale: Physiopathologie, diagnostic et étiologies. EMC-Hépatologie, 7, 1-8. 